\title{
Efektivitas Konseling Wellness Untuk Meningkatkan Psychological Well-Being Lansia
}

\author{
Lucia Hernawati ${ }^{1}$, Praharesti Eriany ${ }^{2}$ \\ Universitas Katolik Soegijapranata \\ herna@unika.ac.id ${ }^{1}$ \\ praharesti@unika.ac.id ${ }^{2}$
}

\begin{abstract}
Abstrak: Jumlah usia lanjut (60-70 tahun hingga meninggal) di Indonesia dari tahun ke tahun meningkat. Pada fase lansia, individu mulai mengalam penurunan fungsi fisikal, kognisi dan relasi bersama teman. Dengan demikian besar kemungkinan psychological well-being lansia menurun dengan indikator kepuasan hidup dan kontribusi lansia pada masyarakatnya menurun. Kegiatan pengabdian masyarakat ini bertujuan untuk membantu lansia untuk meningkatkan kebahagiaannya dengan memberi layanan Konseling wellness selama 7 sesi ( 7 minggu). Melalui layanan Konseling wellness, lansia diajak melakukan self discovery untuk mengevaluasi gaya hidup yang selama ini dijalankan dan merancang serta mewujudkan gaya hidup baru yang sehat holistik (sehat fisik-mental-sosial) agar dapat menjalani hidup dengan memaksimalkan aktualisasi potensi diri dan kontribusi pada masyarakat. Dengan demikian lansia akan merasa lebih puas pada hidupnya dan lebih bahagia (state of psychological wellbeing meningkat)
\end{abstract}

Keywords: Psychological well being, konseling wellness, lansia

\begin{abstract}
The number of elderly (60-70 years old until death) in Indonesia increases from year to year. In the elderly phase, individuals begin to experience decreased physical function, cognition and relationships with friends. Thus, it is likely that the psychological well-being of the elderly will decline with declined life satisfaction and contribution to their community as the indicators. This community service activity aimed to help the elderly increase their happiness by providing wellness counseling services for 7 sessions ( 7 weeks). Through the wellness counseling services, the elderly were invited to evaluate their current lifestyle through self-discovery and to design and apply a new, holistic healthy lifestyle (physical-mental-social health) in order to live a life by maximizing self-actualization and contribution to the society. Henceforth the elderly will feel more satisfied with their lives and happier (the state of psychological well-being increases).
\end{abstract}

Keywords: Psychological well-being, konseling wellness, lansia

\section{PENDAHULUAN}

Keberhasilan pembangunan di Indonesia mampu meningkatkan usia harapan hidup penduduk Indonesia. Sehingga proporsi penduduk usia lanjut di Indonesia pun cenderung meningkat dari tahun ke tahun. Pada tahun 2010 jumlah penduduk usia lanjut di Indonesia adalah
9,5\% dari total keseluruhan jumlah penduduk atau sekitar 22,78 juta. Meningkatnya jumlah lansia di Indonesia sebesar 5,3 juta pada tahun 2000 menjadi 23 juta pada tahun 2010 menandakan usia harapan hidup di Indonesia juga meningkat. (Kemenkes, 2013). 
Fase lanjut usia (lansia) dimulai dari rentang usia 60 - 70 tahun sampai dengan kematian ( Pada fase ini lansia mengalami penuaan (aging) dimana perubahan yang terjadi cenderung menurun (degeneratif). Perubahan tersebut terjadi dari berbagai aspek yaitu aspek fisik, kognitif, dan sosioemosional. Selain itu, lansia memiliki, tugas perkembangan yang merupakan penyesuaian diri terhadap segala perubahan akibat proses penuaan tersebut yang melibatkan fisik-mentalsosial. Dengan kata lain perubahan yang ada harus mampu dilewati oleh lansia dengan sukses (Santrock, 2011)

Stanley \& Cheek ( 2003) menyebutkan lansia menderita sedikitnya satu penyakit kronis, namun banyak diantaranya yang menderita lebih dari satu. Selain berbagai penyakit kronis, lansia juga mengalami masalah psikososial diantaranya adalah memiliki ketidakmampuan fisik, seperti depresi, ansietas, alkoholisme, dan bunuh diri yang terjadi bersamaan, namun belum didokumentasikan secara pasti. Dengan demikian lansia perlu dibantu agar pada usianya yang lanjut dapat hidup bahagia dengan memiliki persepsi yang positif tentang kesehatan fisiknya, mandiri dalam bantu diri dan bepergian kemana-mana, kompeten dalam menggunakan fungsi kognitifnya dan minimal dalam menerima bantuan dari orang lain.

Lloyd (2000) menyebutkan bahwa studi mengenai lansia masih jarang dilakukan padahal merupakan hal yang perlu untuk membantu lansia agar dapat hidup bahagia (well being) khususnya psychological well being (PWB). Rif (dalam Weiss, et.al, 2016) mengembangakan PWB. Disebutnya karakteristik lansia yang bahagia adalah dapat menghargai dirinya sendiri dengan positif termasuk kesadaran akan keterbatasan diri pribadi (self-acceptance), mampu membangun dan menjaga hubungan baik dan hangat dengan orang lain (positive relationship with others), mampu menciptakan konteks lingkungan sekitar sehingga bisa memuaskan kebutuhan dan hasrat diri individu sendiri untuk memberi kontribusi pada lingkungan sekitarnya (environmental mastery), mampu membangun kekuatan individu dan kebebasan personal (autonomy), memiliki dinamika pembelajaran sepanjang hayat dan keberlanjutan mengembangkan kemampuan diri (personal growth) serta memiliki tujuan hidup yang menyatukan usaha dan tantangan yang dihadapi (purpose in life). Lansia yang berada pada state of psychological well being disebut juga successful aging karena mampu 
bertumbuh menjadi tua dengan sehat dan bervitalitas.

Hasil penelitian Hernawati (2019) menunjukkan bahwa lansia di Semarang dapat menerima diri apa adanya. Lansia dapat menilai dirinya secara positif. Penerimaan diri yang positif dapat dilihat dari cara memandang keadaan dirinya secara positif serta bisa menerima keadaan masa lalunya secara bijak tanpa harus menyalahkan diri sendiri maupun menjadi orang lain sebagai penyebab permasalahan. Temuan ini mengindikasikan lansia sehat mental. Kemampuan lansia menerima ketuaannya, berdamai dengan keadaanya membuatnya sehat mental (William, 2011). Disamping itu lansia memiliki relasi sosial yang harmoni dengan orang lain. Ditunjukkan dalam rupa kemampuannya menjalin hubungan yang harmoni dengan orang lain di sekitarnya. Temuan ini didukung teori yang dikemukakan Krause (2008); Phillips, Siu, Yeh, \& Cheng (2008) bahwa kemampuan mengekspresikan diri secara verbal serta dukungan sosial dari keluarga dan teman membuat individu merasa bahagia. Hal ini sejalan dengan pendapat Greetz (1983) bahwa relasi sosial yang harmoni, didalamnya terkandung keakraban, dan saling mendukung membuat indivdidu bahagia.

Tidak semua lansia merasa bebas mengatur hidup dan tingkah lakunya secara otonom. Ada lansia yang tergantung pada orang-orang di sekitarnya. Misalnya anak, menantu, suami/isteri. Suseno (1984) menyebutkan pada budaya Jawa saling tergantung satu sama lain yang membuat individu bahagia. Karena dengan demikian dikembangkan empati, saling toleransi diantara mereka.

Tidak semua lansia turut serta mengatur lingkungannya, memanfaatkan kesempatan yang ada di lingkungan, menciptakan, dan mengontrol lingkungan sesuai dengan kebutuhan. Banyak yang menyerahkan urusan domestik pada anak, menantu, isteri/suami. Suseno (1984) yang mengatakan bahwa pada budaya Jawa saling tergantung satu sama lain yang membuat individu bahagia. Karena dengan demikian dikembangkan empati, saling toleransi diantara mereka.

Tidak semua lansia memiliki tujuan hidup yang jelas. Banyak yang menjalani hidup mengalir saja. Tidak lagi memiliki keinginan khusus untuk dilakukan. Hal ini sesuai dengan budaya Jawa bahwa hidup dengan ikhlas, nrimo dan tidak mengikatkan diri pada hal duniawi membuat hati tenang dan akhirnya bahagia (Suseno, 1984). Beberapa lansia menunjukan semakin religius. Temuan ini sejalan dengan temuan (Yours \& Cullen dalam Lloyd, 2000) yang menyebutkan semakin tua, individu semakin tinggi 
tingkat spiritualnya. Namun ada beberapa lansia yang memiliki tujuan hidup yang jelas saat ini, misalnya ingin mengembangkan usaha, berternak, punya keinginan untuk mengembangakan potensi dirinya.

Tidak semua lansia mengupayakan pertumbuhan dirinya. Tidak semua lansia berkeinginan untuk mengembangkan potensinya dan menginginkan pertumbuhan yang berkesinambungan dalam dirinya, memandang diri sebagai individu yang selalu tumbuh dan berkembang, terbuka terhadap pengalaman-pengalaman baru, memiliki kemampuan dalam menyadari potensi diri yang dimiliki, dapat merasakan peningkatan yang terjadi pada diri dan tingkah lakunya setiap waktu serta dapat berubah menjadi pribadi yang lebih efektif dan memiliki pengetahuan yang bertambah. Fenomena ini dapat dimengerti dengan temuan suseno (1984) bahwa bagi etnis Jawa nrimo itu membuat bahagia.

Seorang tokoh yeng bernama Endraswara (2015) menyebutkan orang Jawa harus merevolusi mentalnya. Orang Jawa tidak boleh berada di zona nyaman bila ingin hidup sehat. Harus proaktif daripada reaktif, harus asertif daripada hanya kompromi. Mental ewuh pakewuh harus direvolusi ke mental gambuh (mental yang paham terhadap suasana hidup yang riil). Mampu berpikir rasional, ikhlas, tulus.
Zaman sudah berubah maka pemikiran juga harus berubah. Pemikiran tentang revolusi mental orang Jawa diatas perlu dipahamkan pada lansia agar dapat hidup lebih bahagia (memiliki state of psychological well being) yang memadai di jaman ini.

Salah satu cara meningkatkan $P W B$ dengan pemberian layanan konseling wellness yang merupakan pemberian layanan konseling kesehatan secara holistik (fisik-mental-sosial). Lansia diberi kesempatan untuk melakukan self discovery gaya hidup yang selama ini dijalani, mengevaluasi dan merancang dan mewujudkan gaya hidup yang lebih sehat. Dengan cara ini lansia akan mengalami proses dan memiliki gaya hidup yang lebih sehat. Semua ini membuatnya lebih bahagia (Myers \& Sweeney, 2008).

Tujuan dari kegiatan pengabdian kepada masyarakat ini untuk memberikan layanan konseling wellness kepada lansia untuk meningkatkan PWB nya

\section{RUMUSAN MASALAH}

Di Klinik Sehati - Banyumanik, Semarang yang merupakan klinik faskes tingkat pertama Badan Penyelenggara Jaminan Sosial Kesehatan (BPJS), berdasarkan wawancara singkat dengan dokter Suzana Dewi Ratih (pengelola Klinik Sehati) tanggal 27 September 2019, diperoleh informasi bahwa total jumlah 
pasien lansia di Klinik Sehati sejumlah 70 orang berusia $60-92$ tahun. Pada umumnya memiliki penyakit fisik bervariasi seperti diabetes melitus tipe 2, hipertensi, jantung, sakit lambung dan persendian. Penyakit fisik yang diderita tersebut diperparah dengan adanya konflik penderita yang notabene lansia dengan anak, menantu, pasangan hidup (isteri/suami), dan teman yang dipicu dengan pikiran negatif pada relasi sosial. Disamping ada pula memiliki masalah kesepian (loneliness) karena suami meninggal dan anak-anak tinggal di luar kota. Ada yang harus beradaptasi dengan fase pensiun. Ada yang selalu jengkel dengan penyakit fisiknya yang membuatnya tidak dapat memiliki mobilitas diri yang memadai. Jadi pada intinya pasien lansia di Klinik Sehati tidak hanya sakit fisik namun berkecenderungan kurang sehat mental dalam hal ini bertendensi berpikir negatif, regulasi emosi kurang memadai, kemampuan beradaptasi pada situasi here and now kurang memadai serta bertendensi tidak sehat sosial. Hal ini terlihat pada adanya konflik sosial.

Dokter Suzana Dewi Ratih menyampaikan tidak memiliki keterampilan dan waktu yang cukup untuk memberikan pendampingan konseling psikologis karena jumlah pasien yang selalu penuh sementara jam praktek terbatas dan pemahaman pada konseling kurang memadai. Oleh karenanya pasien lansia di Klinik Sehati perlu dibantu secara khusus dengan memberikan layanan konseling wellness agar lansia dapat lebih sehat fisik-mental sosial. Dengan demikian diharapkan lansia dapat lebih puas dengan hidupnya dan lebih bahagia.

\section{METODE}

\section{III.1. Perencanaan}

1.1 Menyiapkan materi konseling wellness sesi pertama sampai dengan sesi tujuh

1.2 Bekerjasama dengan Klinik Sehati. Dengan alamat jalan Cemara, Banyumanik-Semarang yang memiliki program untuk lansia untuk memberikan layanan konseling wellness untuk lansia.

1.3 Bekerjasama dengan dokter di Klinik Sehati untuk menentukan 15 orang lansia yang memiliki riwayat kesehatan holistik kurang memadai untuk turut serta dalam aktivitas ini dalam rentang usia 60 - 70 tahun

1.4 Mengadakan pertemuan awal pada 15 orang lansia tersebut dengan tujuan:

a.Menyampaikan maksud dan tujuan kegiatan 
b.Membangun rapport pada lansia

c.Menyampaikan bahwa konseling wellness akan berjalan selama tujuh minggu, dengan frekuensi seminggu sekali, durasi 2 jam.

1.5 Membuatan kontrak yang mengikat secara sosial dan moral. Dengan meminta lansia untuk mengisi informed consent yang menunjukakan kesediaannya untuk mengikuti sesi konseling secara keseluruhan mulai dari sesi pertama hingga ketujuh

\section{III.2. Metode Konseling}

2.1 Dilakukan konseling kelompok dengan 15 orang lansia sebagai konselor dan 1 konselor pada sesi 1 hingga sesi 7

2.2 Pada sesi 1 dilakukan pengukuran PWB secara kualitatif sebagai pretes. Selanjutnya kepada konseli diberikan materi PWB yang memadai melalui konseling wellness yang disampaikan secara verbal oleh konselor dan dilanjutkan dengan tanya jawab

2.3 Pada sesi 2 dilakukan pengukuran wellness (kesehatan holistik) secara kualitatif oleh konselor. Dilakukan dengan cara meminta setiap konseli untuk sharring sebuah masalah yang hingga sekarang dianggap belum selesai dan dirasakan mengganggu kehidupannya.

Selanjutnya konselor mengkaitkan dengan aspek-aspek wellness (creative, coping, social, essential, physical) dan mengajak konseli memahami penyebab masalah dengan teleoanalysis (membuat analisa dengan mengaitkan satu aspek dengan aspek lainnya seperti pengalaman di fase kanak-kanak, komunitas sosial, pendidikan, agama, budaya di masa lalu dengan keluarga, lingkungan sosial, pendidikan, agama, dan politik) untuk lebih memahami dinamika masalah yang dialami dan secara spesifik dapat mengambil kesimpulan penyebab munculnya masalah tesebut dan dikaitkan dengan aspek-aspek wellness. Selanjutnya menentukan goal setting pada aspek wellness yang akan ditingkatkan

2.4 Pada sesi 3 sampai dengan 6 diberikan intervensi dengan mengulas semua aspek-aspek wellness secara maraton dan meminta konseli untuk mempraktekkan di rumah selama 1 minggu serta menceritakan dalam kelompok keberhasilan dan kesulitan dalam menjalankannya dalam seminggu. 
2.5 Pada sesi tujuh dilakukan pengukuran PWB secara kualitatif pada konseli untuk mengetahui tingkat PWB setelah diberi intervensi

\section{III.3. Pelaksanaan}

3.1 Sesi satu dilaksanakan tanggal 15 oktober 2019.

Aktivitasnya adalah (a) pengukuran

PWB; (b) penyampaian materi pentingnya memiliki PWB yang memadai melalui konseling wellness

3.2 Sesi dua dilaksanakan 22 oktober 2019 dengan materi (a) pengukuran wellness (kesehatan holistik), (b) melakukan teleoanalysis untuk mengetahui suber masalah yang dialami dan (3)menetapkan goal setting dari aspek-aspek wellness yang akan ditingkatkan.

3.3 Sesi tiga sampai sesi enam dilaksanakan mulai tanggal 29 oktober 2019 sampai tanggal 19 november 2019.

Pada sesi ketiga konseli diberi materi yang mengulas (a)creative dan (b) coping dikaitkan pada fisik-mentalsosial. Pada sesi ketiga ini diakhir pertemuan konseli diberi pekerjaan rumah (PR) untuk berlatih aspek creative dan coping serta menanggapi masalah yang dihadapinya dengan berpikir positif, mengontrol emosi, aktif beraktivitas, dan memiliki aktivitas yang membuat rileks (me-time) selama 1 minggu.

Pada sesi keempat konseli diawali dengan sharring keberhasilan dan kesulitan mengerjakan tugas yang diberikan serta pembelajaran yang diperoleh. Selanjutnya diberi materi baru yang mengulas (a)social dan (b)essential dikaitkan pada fisik-mental-sosial. Pada sesi keempat ini diakhir pertemuan konseli diberi pekerjaan rumah (PR) untuk berlatih aspek social dan essential serta menanggapi masalah yang dihadapinya dengan pemikiran bahwa kesehatan fisik adalah harta yang bernilai maka tubuh perlu dijaga kesehatannya dengan melibatkan keluarga inti. Disamping individu harus menyerahkan hidupnya pada Tuhan selama 1 minggu

Pada sesi kelima diawali dengan sharring keberhasilan dan kesulitan mengerjakan tugas yang diberikan serta pembelajaran yang diperoleh. Kemudian diberi materi yang mengulas (a)physical yang meliputi konsumsi makanan yang bergizi (seimbang karbohidrat-proteinserat-air-mineral-vitamin) dan olah raga atau aktivitas fisik lainnya seperti menyapu, memasak, mencuci pakaian. 
Pada sesi kelima ini diakhir pertemuan konseli diberi pekerjaan rumah (PR) untuk berlatih mengkonsumsi makanan yang bergizi (seimbang karbohidratprotein-serat-air-mineral-vitamin) dan berolah raga selama 1 minggu.

Pada sesi keenam diawali dengan sharring keberhasilan dan kesulitan mengerjakan tugas yang diberikan serta pembelajaran yang diperoleh. Kemudian dilanjutkan mengulas keseluruhan materi: creative, coping, social, essential, physical yang diarahkan kepada kesehatan fisik-mental-sosial membuat individu mampu menerima diri apa adanya, memiliki relasi sosial yang harmoni dengan orang lain, memberikan kontribusi pada lingkungan sosialnya, otonom tidak tergantung pada siapapun, memiliki tujua hidup, dan menyadari pertumbuhan diri.

Pada sesi keenam ini diakhir pertemuan konseli diberi pekerjaan rumah (PR) untuk berlatih keseluruhan materi yang telah dilatihkan yaitu creative, coping, social, essential, physical dan menyadari adanya perbedaan saat ini lebih mampu menerima diri apa adanya, memiliki relasi sosial yang harmoni dengan orang lain, memberikan kontribusi pada lingkungan sosialnya, otonom tidak tergantung pada siapapun, memiliki tujua hidup, dan menyadari pertumbuhan diri selama 1 minggu.

3.4 Sesi 7 dilaksankan tanggal 26 November 2019.

Pada sesi ketujuh dilakukan pengukuran psychological well being secara kualitatif untuk megetahui ada/tidaknya peningkatan PWB setelah diberi layanan konseling wellness. Selanjutnya kepada seluruh konseli disampaikan terima kasih atas komitmen dan kesungguhan berlatih untuk memiliki gaya hidup sehat holistik. Diharapkan akan terus melanjutkan sendiri setelah konseling wellness ini usai.

\section{HASIL PEMBAHASAN}

Pada sesi 1 setelah dilakukan pengukuran PWB secara kualitatif diketahui status PWB dari total 15 orang konseli sebagai berikut: (a) 3 orang memiliki PWB rendah; (b) 9 orang memiliki PWB sedang; dan (c) 3 orang memiliki PWB tinggi.

Saat konselor mengkaitkannya dengan aspek-aspek PWB (penerimaan diri, relasi positif dengan orang lain, kontribusi pada lingkungan, penyadaran akan pertumbuhan diri, memiliki tujuan hidup). Diketahui yang paling rendah adalah aspek relasi sosial dengan orang lain dan penyadaran akan pertumbuhan diri. 
Diatasnya terdapat aspek tujuan hidup. Yang tinggi adalah aspek penerimaan diri dan kontribusi pada lingkungan.

Pada sesi 2 dilakukan pengukuran wellness untuk menentukan goal setting (menentukan aspek wellness mana yang harus ditingkatkan). Dari 15 orang konseli, (a) 6 orang menetapkan goal settingnya physical dengan mengupayakan pola makan menjadi seimbang karbohidrat-proteinserat-mineral-vitamin dan melakukan atau menambah olah raga/gerak tubuh; (b) 2 orang menetapkan goal setting nya essensial dengan mengupayakan peningkatan spiritualitas, gender identity, cultur identity, dan self-care; (c) 2 orang menetapkan goal setting nya social dengan mengupayakan peningkatan kualitas dan kuantitas relasi sosial dalam bentuk pertemanan dengan orang lain maupun dengan pasangan hidupnya sendiri; (d) 1 orang menetapkan goal setting nya coping dengan mengupayakan peningkatan kemampua mengelola stress, self-worth, keyakinan yang realistis, membuat diri rileks (me-time); (e)4 orang menetapkan goal setting nya creative dengan berupaya meningkatkan fungsi kognisi, kontrol emosi, aktivitas produktif, humor yang positif

Pelaksanaan intervensi selama 4 minggu berjalan seperti yang direncanakan. Seluruh konseli bersungguh-sungguh menjalankan tugas (pekerjaan rumah) yang diberikan. Saat konseling kelompok berlangsung terlihat antusiame peserta dengan bertanya, berkomentar, menceritakan pengalaman diri yang mirip dengan yang di sharring kan peserta lain

Pada sesi 7 dilakukan pengukuran PWB secara kualitatif diketahui status PWB setelah diberi intervensi dari total 15 orang konseli sebagai berikut: (a) 1 orang memiliki PWB rendah; (b) 3 orang memiliki PWB sedang; dan (c) 9 orang memiliki PWB tinggi.

Saat konselor mengkaitkannya dengan aspek-aspek PWB (penerimaan diri, relasi positif dengan orang lain, kontribusi pada lingkungan, penyadaran akan pertumbuhan diri, memiliki tujuan hidup). Diketahui yang paling rendah adalah aspek penyadaran akan pertumbuhan diri. Diatasnya terdapat aspek tujuan hidup. Yang tinggi adalah aspek penerimaan diri, relasi positif dengan orang lain dan kontribusi pada lingkungan.

Selama berlangsung konseling wellness yang telah dicapai oleh konseli

1. Pemahaman secara kognitif akan perlunya gaya hidup sehat (wellness) dan mencapai kepuasan/kebahagiaan hidup (PBW)

2. Mencoba mengaplikasikan gaya hidup sehat pada perilaku nyata selama tiga minggu. 
3. Merasakan dampak bahwa setelah melaksankan pola hidup sehat holistik (wellness) maka tubuh merasa lebih sehat, perasaan lebih tenang, relasi dengan orang lain lebih harmoni, memiliki aktifitas produktif minimal mengurus diri dan urusan domestik rumah, membuat perencanaan hidup.

Yang belum tercapai pada konseling wellness ini:

Pola hidup sehat holistik (wellness) belum menjadi kebiasaan (gaya hidup) secara permanen.

\section{KESIMPULAN}

Sebelum diberi intervensi, dilakukan pengukuran PWB secara kualitatif. Hasilnya diketahui status PWB dari total 15 orang konseli sebagai berikut: (a) 3 orang memiliki PWB rendah; (b) 9 orang memiliki PWB sedang; dan (c) 3 orang memiliki PWB tinggi.

Setelah diberi intervensi dilakukan pengukuran PWB secara kualitatif, diketahui status PWB dari total 15 orang konseli sebagai berikut: (a) 1 orang memiliki PWB rendah; (b) 3 orang memiliki PWB sedang; dan (c) 9 orang memiliki PWB tinggi.

Dengan demikian dapat disimpulkan status PWB lansia meningkat setelah mendapat layanan konseling wellness.

\section{DAFTAR PUSTAKA}

Endraswara, S. (2015). Revolusi Mental dalam Budaya Jawa. Yogyakarta. Narasi

Hernawati, L. (2019). Gambaran psychological well-being lansia di kota Semarang

Kemenkes. (2013). Gambaran kesehatan lanjut usia di Indonesia.

Lloyd, L (2000). Dyingin Old Age: Promoting Well: Promoting WellBeingat The End of Life, Mortality, 1171-118

Myers,J.E,Mobley,

K.A.(2004).Foundation of

Wellness Promotion for

Undergraduate Students.Lessons from Between and Within Group Comparison. Journal of College Counseling, 7, 40-49

Myers J.E, \& Sweeney. T.J. (2008). Wellness Counseling: The Evidence Base for Practice. Journal of Counseling and Development: JCD; 86,482-493

Santrock, John W. 2002. Life-Span Development : Perkembangan Masa Hidup Edisi 5, Jilid I. Jakarta : Erlangga.

Stanley, M. \& Julianne, C. (2003). Well Being and Older People: A Review of The Literature. The Canadian Journal of Occupation Therapy, 70 (1), 55-65

Sweeney, T.J. \& Witmer,J.M. (1991). Beyond Social Interest: Striving toward Optimum Health and Wellness. Individual Psychology, 47, 527-540

Weiss, L.A., Westerhof, G.J., Bahlmeijer. (2016). Can We Increase Psychological Well Being? The Effect Of Interventions On 
Patria : Jurnal Pengabdian Kepada Masyarakat

ISSN : 2656-5455 (media online) Vol. 3 | No. 1 Maret 2021

Psychological PWB: A Meta

Analysis of Randomized

Controlled Trial. Journal Pone

11,6, 1-16 : e0158092.

doi:10.13711.0158092 